\title{
A função socioeconômica da escola na sociedade capitalista (Amazonas)
}

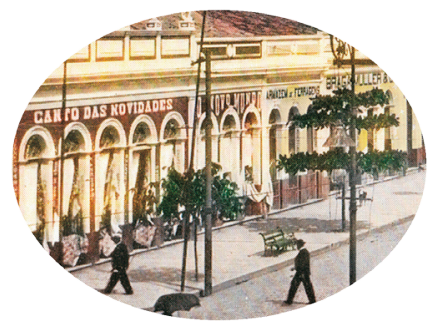

Marcos Praia Simas ${ }^{*}$

\section{Resumo}

O presente trabalho desvela as funções da escola, na perspectiva da globalização e da sociedade capitalista, identificando aspectos que são impostos pela ideologia dominante nos contextos socioeconômico e étnico-cultural. A pesquisa é eminentemente qualitativa norteada pela obra de Frigotto (1995), utilizou-se estatísticas e documentos oficiais e extraoficiais, artigos acadêmicos e científicos.

Palavras-chave: Escola; capitalismo; ideologia; Amazonas.

\begin{abstract}
This study reveals the functions of the school, in view of globalization and capitalist society, identifying aspects that are imposed by the dominant ideology in the socioeconomic and ethnic contexts-cultural. The research is mainly guided by the qualitative work of Frigotto (1995), we used statistics and official and unofficial documents, academic and scientific articles.
\end{abstract}

Keywords: School; capitalism; ideology; Amazon.

\footnotetext{
* Graduado em Pedagogia pela Universidade do Estado do Amazonas (UEA) e em Serviço Social pela Universidade Federal do Amazonas (UFAM). E-mail: marprasi@hotmail.com
} 


\section{Introdução}

$\mathrm{Na}$ sociedade capitalista, as funções primordiais da escola são: manter, reproduzir e sacramentar as relações de hegemonia; ou seja, deixar prevalecer os interesses da classe dominante. No que tange às relações econômicas ou de produção, a "escola de produção" deve criar as condições propícias para que seu público: corpo docente, discente e comunidade; sejam instrumentos da produção, engrenagens fundamentais do gigantesco aparato opressivo do capital.

Os processos de industrialização e urbanização extremamente acelerados nas sociedades pós-modernas, que se tornaram um duro fardo, uma herança maldita, sobretudo para legiões de excluídos dessa evolução desequilibrada de nossas organizações sociais. O duplo papel: desagregação e degradação da condição do ser humano, fato que fica evidente nos trabalhos apresentados por Sebastião Salgado, no documentário: Exxodos (2000) que trata das migrações pelo globo dos desfavorecidos do processo de globalização.

Segundo Cattani (2006) a ampliação das desigualdades entre ricos e pobres no Brasil, onde $10 \%$ dos brasileiros mais ricos controlam mais que $70 \%$ de todas as riquezas do País em detrimento dos demais $90 \%$, que dividem menos de $30 \%$ da fatia do PIB. Tal, disparidade também foi acentuada pelo relatório do Programa das Nações Unidas para o Desenvolvimento (PNUD) divulgado em 2006, que avalia o Índice de Desenvolvimento Humano (IDH) - onde o Brasil ficou nas últimas posições no "ranking" de qualidade de vida na América latina, à frente apenas do Haiti. Dentre os itens que puxaram a pontuação que avalia o desempenho, destaca-se: o saneamento básico, onde $75 \%$ dos lares possuem coleta de esgoto, mas não existe qualquer tratamento desse esgoto em 98\% das casas na maioria das cidades brasileiras; a divisão desigual da renda; e a educação, uma das piores do mundo segundo o mesmo relatório.

\section{A instituição escolar reprodutora: antecedentes históricos}

No século XVI, com a divisão do Brasil nas Capitanias Hereditárias 
(latifúndios), que funcionava apenas a cultura de cana-de-açúcar (monocultura), utilizando o trabalho escravo (índios, depois negros africanos). Por que se investir em educação no Brasil colonial, já que não se precisaria de formação especial da mão de obra, totalmente escrava? Quando o Governador-Geral Tomé de Sousa (1549) chegou ao Brasil fundou a primeira escola de ler e escrever em Salvador um tipo de educação muito regida ao estilo jesuítico (Ratio Studiorum). José de Anchieta "o santo", aos 19 anos, se destacou ao decifrar a língua tupi-guarani (língua geral) e elaborar cartilhas para a catequese (gramática tupi). Mais tarde, temendo-se um predomínio da língua nativa passou-se a exigir o uso exclusivo do português - domínio cultural. Anchieta se utilizando de vários recursos didáticos como: música, teatro, diálogos em verso e poesias para conquistar os curumins, doutrinando-os aos poucos, moral e religiosamente, retirando suas raízes religiosas e causando perda da identidade cultural. No séc. XVIII o panorama ideológico-econômico foi marcado pela ascensão da burguesia, do absolutismo, do mercantilismo e do liberalismo que influenciaram o processo educativo, que sob a tutela dos jesuítas permaneceu nos moldes do século anterior, excludente com mulheres, negros e mestiços. Com o declínio da cana-de-açúcar o foco econômico modificouse para extração aurífera, surgindo com isso uma organização social diferente da anterior cujo principal impacto foi à explosão demográfica. A população colonial salta de 300 mil para 3,3 milhões de habitantes. A expulsão dos jesuítas (1759) gerou a destruição de livros e manuscritos, tornando nosso ensino, que já era precário, mais rudimentar ainda e controlado, firmemente pelo estado, marginalizando índios, negros e mulheres ainda mais (ARANHA, 1996).

O paradoxo da lógica do Estado mínimo e do determinismo tecnológico-mecanicista, que apregoam a transferência das responsabilidades socioeconômicas dos governos para a iniciativa privada e a sociedade civil, transformando a instituição escolar numa grande boia salva-vidas, para tentar sanar as imperícias e o descaso das autoridades com as problemáticas socioeducacionais desde a fundação do Estado brasileiro. Sob os auspícios dos detentores do modo de produção e dos administradores da infraestrutura educacional, que desenvolvem técnicas e métodos para favorecer, sem que os participantes desse processo: alunos, professores e a família, se deem conta do que está acontecendo, ditam os caminhos a serem seguidos pelos demais. 
Ao mascarar e fabricar uma pseudo-realidade, ou ontologia da realidade sintetizada, tornando-a imperceptível ou em alguns casos agradável ou tolerável, a dominação se faz sem custos ou resistências, em muitos casos impossível de ser percebida ou sentida, como é o caso da classe proletária, que vivem numa prisão sem paredes ou grades, uma nova modalidade de escravidão, pois os que são servos não têm a mínima noção de que estão sendo manipulados, treinados para uma vida onde as opções são: a servidão incondicional ou consensual, ou ostracismo e exclusão.

Segundo Adorno (1996) a ideologia dominante visa à manutenção do poder e a disseminação dos mecanismos de exploração. Destarte, ela deve ser intrinsecamente não perceptível, com isso garante-se a eficácia da lógica de legitimação da relação de dominação, que permanece oculta. Em outras palavras, a crítica ideológica tem desvelar estes embustes com o pleno reconhecimento do fato de que é muito fácil mentir sob o disfarce da verdade.

Para Rodrigues (2002) a educação que incorpora a ideologia dominante é reprodutora e perpetua o poder, sem alterá-lo nem questioná-lo, transmitindo aos indivíduos valores que conduzem a subordinação, assegurando a coesão social. A instituição escolar, nesse cenário estagnado, nem tolera questionamentos, nem tenciona levar os indivíduos a uma maior compreensão dos fenômenos sociais. Nas sociedades industrializadas e individualistas, esse processo educativo assume a condição de educação moral para formação de novos conceitos e aprimoramento de seus integrantes, dando origem a um paradoxo: num primeiro momento a educação busca a eqüidade social limitando o alcance dos educandos, por conseguinte, a seguirem a correnteza da sociedade, sem vislumbrarem qualquer chance de questionamentos.

A educação nesta perspectiva deve moldar a sociedade para que esta perpetue o conjunto total de valores sociais, que são auto-suficientes e influenciando a totalidade das instituições como de seus integrantes, para que não se chegue a uma catástrofe social, mostrando as implicações e a importância que neste caso assume a educação, levando seus integrantes a contornarem o individualismo exacerbado pela solidariedade das diferenças, que enfraquece o tecido social na sua essência e que são os pilares da moral social, partindo da primeira noção que Durkheim (1952) dá para os primeiros estágios da educação. 
Os excluídos e a educação para o trabalho

Partindo da ótica de Bourdieu (1988, p.156) "As representações dos agentes variam de acordo com sua posição (e com os interesses associados a ela)", sobre as representações atribuídas aos negros no Brasil e no mundo, chegamos à conclusão que tudo que foi dito, escrito ou representado no cinema, teatro, ou seja, em todas as manifestações culturais e artísticas sobre os negros, foram distorcidas, minimizadas ou simplesmente excluídas dos registros históricos oficiais ou extra-oficiais. O negro, por questões culturais, religiosas, étnicas ou apenas por puro desconhecimento, ou preconceito daqueles que desde o início olharam com desdém tudo que fosse diferente de si mesmo, vem ao longo dos anos sofrendo várias diferenciações que o colocam como ser humano de segunda categoria.

Com o desenvolvimento da civilização, o homem, tratou de engendrar mecanismos que dispusessem e legitimassem suas práticas hediondas de escravidão, por exemplo: no Egito, os escravos (judeus), subjugados, oprimidos não tinham nenhuma participação na elaboração de documentos que relacionassem ou mesmo descrevesse seu modo de vida, sua cultura, sua história, se justo ou não era sua condição de acordo com o momento histórico, naquele determinado momento não havia um único egípcio sequer que discordasse de que os judeus eram seus escravos por natureza, pois foi legitimada pelas autoridades do Egito à época. Em termos de representação, o afro-descendente tem sido associado ao longo dos séculos, de maneira pejorativa, pois eles não têm, nem nunca tiveram alguma representação política expressiva, segundo a história oficial. Mas, sabem-se que houve inúmeras dinastias ou mesmo nações organizadas e geridas por negros por faraós negros, os Núbios, grandes construtores de pirâmides, que é uma conquista da civilização mundial, um feito esplendoroso de engenharia e arquitetônica, no entanto, poucas pessoas sabem disso, porque alguns acharam que só se deveria dar importância aos faraós brancos.

Há razões de cunho religioso que disseminaram a idéia de que o negro era e sempre será escravo (BOSI, 1996), a origem ancestral do preconceito remonta o livro de gênesis, onde Noé, um dos patriarcas de duas das maiores religiões universais, profetiza e preconiza que um de seus netos Canaã (filho de Cão, que significa preto ou quente) seja vítima eterna da escravidão. 
O negro e sua representação ante os aspectos político-ideológicos nos remetem ao seguinte fato, na história, o homem de cor parda ou escura, foi cognominado "negro", não somente por seu biótipo, mas também por implicações quanto ao ser social, invocando justificativas para colocá-lo como mão de obra escrava, retirando seu papel de agente enquanto construtor da própria imagem e emancipação intelecto-cultural, desse modo à imagem que é passada para a sociedade e para o próprio negro é uma montagem, uma visão hegemônica de como deve ser e se portar o "negro ideal".

$\mathrm{Na}$ civilização ocidental moderna, nos moldes da Grécia antiga, onde o Estado patrocinava ampla massificação da discriminação e do escravismo [...] "mas apenas homens políticos que, sós ou em companbias de outros, são ou podem ser senhores dos interesses comuns da cidade" (ARISTÓTELES, 1995, p. 96), ou seja, quem não é da classe dirigente não pode gozar dos direitos da cidadania, o trabalho manual é prática das classes inferiores da sociedade, o ócio e o lazer são prerrogativas das elites.

Assim, fica fácil entender de onde vem todo este preconceito por "bárbaros, estrangeiros etc." e porque até tempos modernos a legislação justificava e até estimulava uma cultura de diferenciação, exatamente como a descrição de cidadania presente no Inciso I, Artigo $6^{\circ}$, da Constituição brasileira de 1824 .

A história do afro-descendente não tem nada de romantismo, pelo contrário o uso da escravidão para sustentar as bases da economia no Brasil foi um dos episódios culminantes, de inúmeros atos de infâmia cometidos ao longo dos tempos. A maioria dos africanos que foram abduzidos morreu ou foi acometido por enfermidades graves, físicas, psicológicas e morais, que mais tarde os incapacitaram para a vida:

Pela metade do século XIX, a força de trabalho da economia brasileira estava basicamente constituída por uma massa de escravos que talvez não alcançasse dois milhões de indivíduos. Qualquer empreendimento que se pretendesse realizar teria de chocar-se com a inelasticidade da oferta de trabalho. O primeiro censo demográfico, realizado em 1872, indica que nesse ano existiam no Brasil aproximadamente 1,5 milhão de escravos. Tendo em conta que o número de escravos, no começo do século, era de algo mais de um milhão, e que nos primeiros cinqüenta anos do século XIX 
se importou muito provavelmente mais de meio milhão, deduz-se que a taxa de mortalidade era superior à de natalidade (FURTADO, 1964, p.141).

Na verdade, o que aconteceu no Brasil foi uma reedição do feudalismo, só que muito mais nefasto, pois ao negro, era negada a condição de humanidade, sem que ninguém se importasse com seu destino, se este era dotado de emoção, de sentimentos ou quiçá de uma alma! O negro na condição de vassalo e o europeu de senhor, o escravo era a base da economia da colônia, uma "commodity", digamos assim, porque tinha valor de troca e de uso, é só nos lembrarmos de que a Bolsa de Valores de Nova York era um mercado de escravos. O escravo não era remunerado, trabalhava até a exaustão, sofria tratamentos desumanos, alimentação precária, não gozava de férias, décimo terceiro, ou seja, nenhum benefício trabalhista e por 380 anos permaneceram nesta condição sem que ninguém se importasse.

Nas representações artísticas, podem-se citar as novelas e como elas trazem uma visão romântica da escravidão, a figura de alguns patrões benevolentes, amigos dos que ao mesmo tempo eram explorados. Nas novelas, no teatro e no cinema, a imagem do negro é associada à violência, as drogas, ao crime em geral etc. Nas artes o fato de não mencionar ou referir-se mesmo que remotamente aos negros denuncia o descaso e o grau de importância desta para a sociedade. A falta de referencial artístico sugere um comportamento não de negligência, mas de sublimação, de exclusão, algo premeditado e engendrado para que o homem de cor negra não se situe no espaço e no tempo, sabe aquela frase popular - preto não é gente - nesse cenário de inexistência, faz sentido.

O momento histórico de lutas e tensões entre classes, que culminou com a soltura do afro-descendentes dos grilhões da escravidão objetiva, para um tipo de escravidão simbólica, é cheia de passagens em "branco", silêncios, desfaçatez e com o papel inverossímil dos fatos, por exemplo: Zumbi, um dos personagens mais enigmáticos da historia e da luta pela liberdade dos negros africanos seqüestrados por agentes do comércio inescrupuloso nas colônias americanas, um herói? Esquecido pelas historietas convencionais, que trataram de deturpar o papel de importância e relevância que são desencadeados pelas atitudes heróicas de homens como Ele. Não aceitando como natural à escravidão e a opressão, agindo e dando esperanças de dias melhores, sem fantasias, porque não era fácil a vida de fugitivo, ao resgatar Zumbi e seu papel: 
É um fato cultural porque é um fato político; é um fato político porque rompe com a política cultural dominante. Reflete, na verdade, outra forma, de engajamento político do militante negro nos processos sociais. Revela um ponto de vista humano, capaz de romper as fronteiras da raça. Arrebentando a geografia da pele e da cor (CARDOSO, 1986, p. 66).

O engajamento político torna-se mais individual e menos coletivo quando a exclusão dos processos sociais, sobretudo dos educacionais condiciona os sujeitos à sujeição e ao imobilismo. De acordo com Bourdieu não se deve procurar milagres nesse sistema educacional dominado pelo sentimento de oposição de classes

[...] o milagre que esperaríamos no íntimo do nosso coração: a escola, como universo preservado, ilhéu de pureza - à porta da qual se deteriam às disparidades e as lutas sociais, esse milagre não existe: a escola faz parte do mundo [...] A escola limita-se a confirmar e reforçar um habitus de classe, que constitui o fundamento real de todos os progressos escolares. Por isso a escola só triunfa em relação àqueles que beneficiaram para lá do recinto escolar e bem antes de lá entrarem, no seio familiar, dos hábitos de família, de certo estilo de vida (BOURDIEU-PASSERON apud SNYDERS, 1976, p.18-23).

O que nos lembra do famoso conselho de Voltaire, baluarte do Iluminismo francês, ao Arquiduque da Prússia: "A canalha (as massas) é indigna de ser esclarecida [...] é essencial que haja cozinheiros ignorantes [...] e o que é de lei é que o povo seja guiado e não seja instruído" (ARROYO, 1987 apud FRIGOTTO, 1995, p. 33). Ao passo que Diderot aconselhou a imperatriz da mesma Prússia à universalização do ensino. O ponto de vista de Voltaire era também compartilhado por outros filósofos entre eles o político francês, Desttut de tracy, que dizia: 
Os homens da classe operária têm desde cedo necessidade do trabalho de seus filhos. Essas crianças precisam adquirir desde cedo o conhecimento e, sobretudo, o hábito e tradição do trabalho penoso a que se destinam. Não podem, portanto, perder tempo nas escolas. [...] Os filhos da classe erudita, ao contrário, podem dedicar-se a estudar durante muito tempo; têm muitas coisas para aprender para alcançar o que se espera deles no futuro (ARROYO, 1987 apud FRIGOTTOO, 1995, p. 34).

Como vimos, a opinião dos intelectuais é diversa em relação ao tema, mas o papel desses, infelizmente, ao longo dos tempos, foi de reforçar os que detêm o poder a continuarem no poder, a perpetuação, organização ou reorganização das formas de manifestações de poder. A saída para esse imbróglio encontrase na reorganização intelectual e política das massas, mas como será possível se a peneira da educação, que é extremamente seletiva, privilegia poucos, apenas os "capazes"! Os desvalidos encontram pouco ou nenhum amparo por parte da escola pública. Como contornar esse problema? Bourdieu nos mostra que no mundo capitalista a escola é dualística: para os desvalidos, que por conta das condições materiais estagnadas e insuficientes, encontram-se no lugar comum da distinção e da descriminação, nas ocupações periféricas ou descartadas pelos herdeiros dos dirigentes e dos comensais. Para os ricos, que possuem maior capital simbólico, linguístico e cultural, o que os ajuda a manter um padrão, que é caracterizado e auxiliado pelos habitus incorporados de classe, ocupam condições de destaque e de comando "A escola persuade da legitimidade da sua exclusão as classes que exclui, impedindo-as de perceber e contestar os princípios em nome dos quais ela as exclui..." (BOURDIEUPASSERON apud SNYDERS, 1976, p. 80).

Neste sentido, Althusser (1985) diz que a classe hegemônica detém o capital cultural, assegurando seus benefícios através dos tentáculos repressores Exército, Polícia e Tribunais, essa repressão favorece a classe dominante. Quando uns dominam os outros, o que acaba sendo justificado e institucionalizado a reprodução através condição mental do sistema a partir da produção material, reproduzindo a ideologia dominante e onde sua principal função é disfarçar as contradições existentes e torná-las imperceptível aos olhos servis, através dos mais variados "campos", ou Aparelhos Ideológicos (escolas, igreja, família, 
jurídico, político, sindical, informação e cultural) resguardando e assegurando a perpetuação dos mecanismos de dominação.

O campo escola, como veículo superestrutural disseminador ideológico principal, reproduzindo ao fazer com que os que estão dominados não percebam sua exploração e ainda que absorvam inconscientemente a pseudorrealidade, os valores burgueses, assim como habitus do consumo, até mesmo passando a lutar pela manutenção da exploração - como é possível? A escola reproduz as diferenças sociais e perpetua o status quo, é discriminadora e repressiva.

Segundo Bourdieu (1988) a escola transforma a violência ancestral em violência simbólica, que não se perfaz em estado translúcido, não decifrável aos olhos leigos, o que desfaz a ilusão de que este veículo, a escola, seria neutro em relação às contradições no meio social. Isto acaba gerando herdeiros desta estagnação social com uns privilegiados e outros totalmente desfavorecidos. Com a ideia do habitus, Bourdieu nos ensina que existem muitas diferenças no contexto escolar. Então... - A escola não pode ser pensada apenas por um único vórtice! As crianças oriundas de condições sociais mais favoráveis sempre vão levar vantagem em relação às que não tiveram as mesmas condições socioeconômicas de vida. Por exemplo: Uma criança que vem da classe alta, viaja, tem acesso à Internet, com seus pais participando de discussões políticas e sociais, tem um tipo de comunicação que mais se assemelha à encontrada na escola, ou seja, maior quantidade de "habitus sociais incorporados", que o predispõe para assimilar uma maior quantidade capital simbólico para dominar os campos, evoluindo para “capital cultural” que se transforma em poder, hegemonia; Agora, veja outra criança da mesma faixa etária, que não tem Internet, não saí do bairro onde vive, mora em condições físico-sanitárias insalubres, sua família é fragmentada, nunca ouviu falar de política - a não ser durante as eleições. Ela não entende muitas palavras usadas por seus professores, isso nos indica que esta criança tem menos "habitus sociais incorporados", que seus pares burgueses. Portanto, menos capital simbólico, com isso não possui capital cultural, não participa das decisões vitais dos campos sociais, inclusive as que vão determinar o seu próprio destino. As classes hegemônicas podem justificar o insucesso escolar através dos capitais simbólicos controlados por estes, que são dispositivos ideológicos dentro de uma realidade histórico-cultural e educacional, repassando a culpa do insucesso para os "menos capazes", onde 
na verdade esta culpa é do sistema educacional desigual, que favorece quem tem maior quantidade de habitus, que domina mais campos e capitais simbólicos, isto se transforma num ciclo vicioso, onde os que detêm o controle dos campos formadores do Estado sempre serão privilegiados. Contudo, apesar das críticas à escola, enquanto meio da exploração capitalista, mesmo assim deve se ressaltar que ela é o campo principal de lutas para se conquistar quaisquer mudanças na sociedade envolvente.

A condição de não esclarecimento ou mesmo de uma instrução elementar, em termos do nível sociotecnológico de nossos dias, fica evidente com as pérolas de sabedoria de Voltaire, ou melhor, de visível desprezo pela condição humanística do ser. Mesmo dentro da lógica pós-moderna, que impede o acesso das massas a maior autonomia, acabando por torná-los mão de obra barata e dócil. A visão da segregação não é um ato espontâneo do ser humano, ao contrário, essa visão foi disseminada pelas categorias dirigentes para confundir, na verdade, utilizou-se de uma tática militar - dividir para conquistar! Infelizmente, as pessoas encontram-se envoltas numa névoa espessa, construída exatamente para obstruir seus sentidos, não conseguindo enxergar essa tática, ou seja, a legitimação da competição a todo custo, em outras palavras a lei da selva!

\section{Evolução sociohistórica da escola no amazonas}

Não se pode dissociar o processo educacional acontecido no Amazonas do contexto socioeconômico-histórico brasileiro. $\mathrm{Na}$ época do fatídico "descobrimento", o conflito cultural, ou melhor, etnocídio de proporções épicas. O processo de educação institucional era inexistente, pois havia um processo educativo rudimentar, de caráter oral. Até as criações das primeiras vilas, dos jesuítas e dos famigerados descimentos. Há relatos de que muitas das crianças indígenas retiradas das aldeias para serem "instruídas", foram, na verdade, amarradas e afogadas durante as viagens. Milhões de indígenas que não aceitaram as imposições (educação jesuíta), pelos "colonizadores", onde sua educação era um doutrinamento religioso, voltado para docilização de seus corpos (FOUCAULT, 1977) para o trabalho. A base econômica da época era o comércio das especiarias exóticas da região. 
Durante o período áureo da borracha, meados do século XX, a educação também não conseguiu alçar voo, pois, aos coronéis não era interessante que as massas de trabalhadores (seringueiros) tivessem uma educação, mesmo que rudimentar. Foi um período de muita pujança econômica, segundo cálculos do ministério do interior à época o comércio de borracha representava mais que $50 \%$ do PIB, no entanto o crescimento econômico não representou avanços em políticas educacionais. Uma pena! Se as autoridades da época tivessem esquecido sua ganância e sede de poder insaciável, talvez conseguissem enxergar adiante de seus narizes e vissem que um investimento maciço em educação traria muitas vantagens no longo prazo, para a Amazônia e para o País. Houve evolução artística e cultural, mas, investimentos em educação continuavam fora de cogitação. Alguns chamam esse período de grande ou primeiro ciclo de desenvolvimento, sobretudo ao analisarmos o que houve, foi apenas um aumento da renda de pouquíssimas famílias, que mais pareciam clãs poderosos, mas a maioria da população não conseguiu obter um ganho substancial e duradouro; houve ainda o inchaço das cidades gomíferas e das capitais da belle epoque. O segundo ciclo, ou o processo de industrialização patrocinado pelo regime militar, em conluio e gerenciado pelos EUA. A ordem tecnocrata trouxe consigo um modelo criado e totalmente pronto pelo organismo norteamericano de auxílio (controle) externo (USAID) que acabaram por criar leis para sacramentar o pacto para enterrar de vez a educação no Brasil. A lei tecnicista institucionalizava o modelo escolar instrumentalista, ou seja, treinar mão de obra barata e capacitá-la para trabalhos específicos. Nascia aí, um largo processo de fragmentação da educação brasileira - que não era das melhores - e o Amazonas abraçou com unhas e dentes esse modelo até os dias de hoje.

\section{Projeto de transformação do conhecimento e habilidades}

Dermeval Saviani (1980), afirma que a escola pública não saiu do âmbito estrutural, ou seja, ainda não foi sistematizada, porque todos os modelos encontrados no País foram importados, levando em consideração apenas uma realidade exterior a nossa. Saviani diz que a LDB é inoperante, a alternativa Crítica Social dos Conteúdos se implantada seria fundamental para despertar no homem o caráter inovador e através do trabalho-livre, sua própria existência material, assim como na natureza e na cultura. O educando não seria um corpo 
dócil, nem coadjuvante, mas protagonista, livre da imposição do trabalho em prol do capital, num espetáculo real e transformador dentro da sociedade. Se a escola falhar na sua missão modeladora e castradora do indivíduo, que na visão dos controladores da estrutura capitalista se perderiam os corpos para a liberdade. O primeiro embate deve ser a superação do processo que colocou a administração escolar, assim como todo o sistema educacional, a serviço da dominação e reprodução dos interesses dos grupos sociais hegemônicos.

Já na proposta de salvação de Michel Foucault (1977), os educadores seriam os chamados corpos livres, indivíduos que conseguem driblar as coerções dentro do âmbito escolar e das outras instâncias sociais, não caindo no ciclo vicioso da docilização, rompendo o paradigma de não permitir que seus corpos sejam utilizados apenas para o trabalho, tornando-se corpos livres.

Para tanto é necessário driblar os mecanismos de alienação (Marx \& Angel, 1974), que são acentuados pela divisão sociotécnica do trabalho e como o trabalho molda tudo que está erguido sobre ele, como um edifício em que sua fundação é a vida material e por isso transforma a superestrutura (vida mental - idéias), nessa relação dialética em que os campos superestruturais dependem da base social para subsistir. A chave para entender o processo de luta pelo poder na sociedade primitiva ou atual é o trabalho, pois, a partir deste, o homem transforma o mundo. Como o trabalho acabou sendo tirados das mãos operárias, estes passaram a não controlar mais os processos, que foram sistematizados, divididos em estágios para ele, homem, não entendessem por completo as atividades desenvolvidas e acabando por relegar ou docilizar seus corpos para as atividades em si, que foi o fator essencial na construção do mundo cultural de hoje. O trabalhador ao perder sua autonomia, sendo inconscientemente iludido e escravizado, alienando através de processos ideológicos, teve sua vida mental subtraída de parâmetros meramente subjetivos, despojados de qualquer sentido prática e objetivo para a vida dos mesmos.

Veja o exemplo da Coreia do Sul, que investe $20 \%$ de seu PIB em programas educacionais., e o Chile, onde 10\% das riquezas do país estão transformando a situação educacional. Entretanto, o Brasil e mais particularmente o Estado do Amazonas, seguem na contramão do desenvolvimento global, investindo respectivamente, 3\% em nível nacional e 4\% do PIB regional (Estado do Amazonas) no quesito educação. E mais, no Brasil, os custos operacionais (gestão administrativo-burocrática) consomem mais de 60\% dos recursos, 
mas isso não significa melhores salários, mais empregos ou investimento em capacitação dos docentes (capital humano). As distorções não param por aí, $\mathrm{R} \$$ 926,00 é o valor gasto pelo Governo Federal com cada aluno no ensino fundamental, ao passo que um aluno do ensino superior custa aos contribuintes a bagatela de $\mathrm{R} \$ 10.054,00$, quase 11 vezes mais.

$\mathrm{Na}$ Região Norte o analfabetismo gira em torno dos 29,1\% do total de habitantes. No Amazonas, segundo o último senso IBGE (2004), as taxas de analfabetismo absoluto são da ordem de $9 \%$ e analfabetos funcionais são $22,1 \%$ na área urbana. Na área rural, esses números são bem maiores, saltam para $22 \%$ de absolutos e $47 \%$ para os funcionais conforme dados da pesquisa. A Educação especial, no Amazonas, investiu recursos da ordem de 350 mil reais, 0,00625\% do orçamento do Estado, ou 0,06\% do orçamento destinado para educação por parte do governo amazonense, aproximadamente, no último balanço do exercício 2006/07 alcançou receitas da ordem de 5,6 bilhões de reais. O Governo Federal repassou ao estado do Amazonas 76 mil reais para investimento na educação especial. Em relação aos investimentos em educação indígena, o Governo Federal, não repassou um único centavo, justamente para o Estado que possuem mais que $90 \%$ da população indígena remanescente.

\section{Considerações finais}

Ao situar no espaço-tempo as origens do caos educacional encontrado atualmente. O referido trabalho se constitui de análises de todas as implicações que envolvem o tema e a busca pela proposta teórico-metodológica, que englobe a visão histórico-dialética. A abrangência do projeto e suas nuanças constituem-se de questionamentos, reformulações, novas perspectivas e de maneira que possamos entender os porquês do fracasso da educação brasileira. A ausência e/ou insuficiência de investimentos públicos no quesito educação é ou não um desleixo? A educação é uma questão estratégica para a maioria dos países industrializados, mas o Brasil foge a esta regra. Então como resolvê-lo então?

As questões sobre a administração escolar e de seu papel como instrumento de manutenção e perpetuação do status quo. Ele sugeriu como forma de reverter esse quadro lastimável no cenário educativo brasileiro, que se deveria implantar uma educação que vise à emancipação do sujeito, 
de cunho crítico e político, que desnude o clima de aparente calmaria, forma velada de jogar para debaixo do tapete as distorções socioeconômico-históricas encontradas no Brasil desde a sua fundação.

A formação do cidadão crítico é possível à margem das ciências? Igualmente, professores que problematizam, buscando soluções para construção dos saberes profissionais e sociais, se tornando parceiros/ colaboradores da instituição escolar e da comunidade. Processando de maneira dinâmica e subsequente, mudando a configuração de docentes-receptáculos para docentes construtores, transformadores e reformuladores de saberes e conhecimento, participando ativamente dos projetos, não como animais de laboratório que ficam sendo observados por técnicos "especialistas" das universidades, e sim, como os próprios agentes dessa transformação.

Portanto, a escola deslocada do espectro reprodutor dos interesses hegemônicos deve suscitar o inter-relacionamento entre os agentes do processo educativo, visando uma participação democrática efetiva, sem intermediários ou que interesses pessoais e vaidades atrapalhem o bom andamento dos trabalhos conjuntos. O profissional da educação, o educador tem papel essencial nesse processo, pois sendo esse papel descrito por Gramsci, só que com o nome de intelectual orgânico, poderá ser protagonizado pelos docentes que se engajarem nessa corrente de democratização e valorização do ensino. Em decorrência do projeto de transformação dos conhecimentos e habilidades, bem como do modus operandi do educador e de sua participação ativa nesse processo, com maior aperfeiçoamento teórico-metodológico e crítico.

\section{Referências}

ADORNO, Theodor et al. Um mapa da ideologia. Rio de Janeiro: Contraponto, 1996.

ALTHUSSER, Louis. Aparelhos ideológicos de Estado. 2. ed. Rio de Janeiro: Graal, 1985.

ARANHA, Maria. Historia da Educação. 2. ed. São Paulo: Moderna, 1996.

ARISTÓTELES. A Política. Bauru: Edipro, 1995.

BOSI, Alfredo. Dialética da colonização. São Paulo: Companhia das Letras, 1996. 
BOURDIEU, Pierre. Coisas ditas. São Paulo: Brasiliense, 1988.

BRASIL, IBGE. Censo Demográfico 2004. Disponível em: < http://www.ibge.gov. br/http://www.ibge.gov.br/brasil em sintese/default.htm >. Acesso em: 3 nov. 2006.

. MP/RJ. CONSTITUIÇÃO: Carta de lei de 25 de março de 1824. Disponível em: <http://www.cmp.rj.gov.br/petro1/constituicao.htm>. Acesso em 30 out. 2006.

. Biblioteca Nacional. Coleção da Biblioteca Nacional; Unesco: 1999. Disponível em: < http://consorcio.bn.br/escravos/introducao.html>. Acesso em 30 out. 2006.

CARDOSO, Hamilton. O Resgate de Zumbi. Lua Nova, Cultura e Política, v. 2, n. 4, p. 63-67, jan./mar. 1986.

CATTANI, Antônio. A produção do conhecimento sobre as desigualdades socioeconômicas - Palestra realizada a 19 de maio de 2006 - Escola Normal Superior, Universidade do Estado do Amazonas - Brasil.

DURKHEIM, Émile. Educação e sociologia. 3. ed. Tradução de Lourenço Filho. São Paulo: Melhoramentos, 1952.

FOUCAULT, Michel. Vigiar e Punir. Petrópolis: Vozes, 1977.

FRIGOTTO, Gaudêncio. Educação e a crise do capitalismo real. São Paulo: Cortez, 1995.

FURTADO, Celso. Formação Econômica do Brasil. S. Paulo: Ed. Fundo de Cultura, 1964.

MARX, Karl; ENGELS, Friedrich. A ideologia alemã. São Paulo: Martins Fontes, 1974.

ONU/PNUD. IDH 2006 - Índice de desenvolvimento humano. Disponível em: <http://www.pnud.org.br/saneamento/reportagens/index. php?id01=2389\&lay=san $>$ Acesso em: 13 dez. 06.

RODRIGUES, Alberto. Sociologia da Educação. 3. ed. Rio de Janeiro: DP\&A, 2002.

SALGADO, Sebastião. Êxodos. São Paulo: Companhia das Letras, 2000.

SAVIANI, Dermeval. Educação: do senso comum a consciência filosófica. São 
Paulo: Cortez, 1980.

SNYDERS, Georges. Escola, Classe e Luta de Classes. 2. ed. São Paulo: Centauro, 1976. 